\title{
WACANA IDA RATU GEDE MAS MACALING DALEM NUSA PENIDA KLUNGKUNG
}

Oleh :

I Made Dian Saputra

\begin{abstract}
Abstrak
Masyarakat Hindu di Bali memandang waktu sebagai sebuah hal yang penting. Waktu atau Kala hadir sebagai ruang yang dihubungkan dengan mitos magi. Hubungan tersebut dapat dilihat pada mitos Sasih Keenem yang diyakini merupakan fase waktu datangnya epidemi atau wabah. Seringkali mitos Sasih Keenem juga dihubungkan dengan wacana Ida Ratu Gede Mas Mecaling sebagai sosok magi penebar wabah dan bencana dijagat Bali. Menariknya, citra Ida Ratu Gede Mas Mecaling Dalem Nusa Penida justru seolah-olah menjadi mitos hidup dan "sesembahan" bagi mereka para balian, pengiring, dan penekun ilmu kebatinan. Belakangan marak sekali orang-orang ngayat (memuja) beliau sebagai objek pemujaan, dan lebih menariknya beragam versi wacana magi tentang beliau berkembang dalam masyarakat. Atas dasar tersebut, menjadi menarik hal tersebut dikaji dalam tulisan ilmiah berikut sehingga menemukenali nilai dan makna dalam lingkarkajian wacana magi.

Kata Kunci: Wacana Ida Ratu Gede Mas Mecaling, Mistik, Magi, Sakti
\end{abstract}

Hingga kini ada banyak versi wacana dengan waktu(sasih kaenem). Sebagaimana tentang citra Ida Ratu Gede Mas Mencaling dalam emik atau kepercayaan masyarakat Dalem Nusa Penida, baik dalam ragam sastra Hindu Bali, bahwa sasih keenem selalu dan tutur lisan. Namun dibalik keragaman versi dihubungkan dengan "musim wabah". Menarik tersebut, wacana tentang beliau selalu dikaitkan dan uniknyakeyakinan tersebut menjadi suatu 
hal yang fenomenal. Hal tersebut disebabkan wacana Ida Ratu Gede Mas Mecaling Dalem Nusa Penida selau dihubungkan dengan "mitos", bahwa ketika sudah sasih keenem, beliau dengan rencang (abdi setia) akan pergi ke tanah Bali dan menebar epidemi (wabah).

Wacana tersebut bahkan dapat dinyatakan sudah menjadi "mitos hidup" dalam lingkungan sosial masyarakat Hindu Bali. Mengacu pada teori mitos, mitos hidup (living traditions) merupakan ingatan kolektif yang mendorong manusia untuk meningkatkan keyakinan pada hal-hal yang magi.Adapun magi menurut uraian Koentjaraningrat dalam bukuTeori Sejarah Antropologi I adalah kepercayaan dan praktik manusia dalam keyakinannya terhadap hal yang gaib. Magi juga disamakan dengan upacara dan rumusan verbal yang memproyeksikan hasrat manusia ke dunia luar dan kekuatan di luar diri manusia. Bagi masyarakat Hindu Bali mitos berhubungan dengan hal yang magi, dan justru dipandang sebagai sebuah kejadian historis dan faktual serta dapat dijadikan medium bagi yang meyakini untuk mencapai “pembebasan”. Maka dari itu, beberapa mitos di Bali tetap eksis hingga saat ini.
Atas keberadaan mitos tersebut, banyak umat Hindu Bali dan luar Bali melakukan perjalanan suci ke Pura Dalem Ped Nusa Penida untuk memohon anugrah kepada Ida Ratu Gede Mas Macaling Dalem Nusa Penida. Terlebih mitos berkembang, bahwa Ida Ratu Gede Macaling adalah tokoh gaib yang sakti, dan dijadikan objek pemujaan bagi orang-orang yang melakoni perdukunan di Bali.Banyak fenomena sekarang para pengusadha (dukun) melakukan perjalan suci ke pura Dalem Ped untuk memohon berkah kepada Ida Ratu Gede Mas Mecaling Dalem Nusa Penida untuk memohon taksu. Tidak saja para pengusadha, masyarakat Hindu Bali semakin marak melakukan tirta yatra ke Dalem Nusa sehingga menimbulkan kesadaran kolektif bagi masyarakat Bali untuk meyakini mitos ini.

\section{Kedudukan Wacana Ida Ratu Gede Mas Mecaling Dalem Nusa}

Wacana Ida Ratu Gede Mas Macaling Dalem Nusa Penida dalam lingkungan masyarakat Bali memiliki kedudukan yang penting. Nampak wacana tersebut berada dalam ruang lingkup versi mitos itu sendiri, 
kepercayaan para pangiring dari Ida Ratu

Gede Mas Macaling Dalem Nusa Penida, kemudian peranan sastra babad sebagai sebuah penguat keyakinanmereka.

Versi mengenai wacana Ida Ratu Gede Mas Macaling Dalem Nusa Penida memang tersebar dalam kehidupan sosial masyarakat Bali. Wacanaini berkembang dan hidup sejalan dengan waktu dan keadaan masyarakat Bali itu sendiri, namun dengan tetap mempertahankan sisi gaib dan magis yang menjadi magnet kuat bagi wacana Ida Ratu Gede Mas MacalingDalem Nusa Penida. Wacana tentang tokoh ini tersebar dengan berbagai varian atau versi yang masing-masing memiliki perbedaan. Keberagaman wacana ini diturunkan oleh leluhur masyarakat Bali dengan dua cara, yaitu (1) cara lisan, yakni wacana Ida Ratu Gede Mas Macaling Dalem Nusa Penida, dikisahkan kembali oleh orang-orang Bali dari mulut ke mulut. (2) Cara tertulis, yakni cara ini lebih pada perekaman dengan sastra atau literatur yang memuat langsung kisah Ida Ratu Gede Mas Macaling Dalem Nusa Penida. Baik dalam dunia babad dan lontar yang secara umum kebenarannya diakui oleh masyarakat Bali secara keseluruhan.
Masyarakat Bali membuat wacana Ida Ratu Gede Mas Macaling Dalem Nusa Penida menjadi sangat hidup dan berkesan secara sisi batiniah. Sebab dalam narasinya, selalu bersentuhan langsung dengan kehidupan sosioreligius masyarakat Bali. Maka varian dari wacana Ida Ratu Gede Mas Macaling Dalem Nusa Penida menjadi sangat banyak muncul. Ini tergantung dari narator pertama, kemudian diterima oleh pendengar, dan pendengar tersebut menjadi narator untuk orang lain. Demikian seterusnya disebar luaskan dari generasi ke generasi, lebih pada cara lisan.

Wacana Ida Ratu Gede Mas Macaling Dalem Nusa Penida bagi para pangiring merupakan sebuah kejadian faktawi dan keyakinan mereka atas kebenaran dalam mitos ini sungguh sangat luar biasa. Jadi mereka mendasarkan keberadaan wacana tersebut berdasarkan atas "kepercayaan" dan "pengalaman" mereka terhadap citra tokoh Ratu Gede Mecaling. Jadi, mereka tidak akan terlalu memusingkan diri dengan benar dan tidak mitos tersebut. Satu hal yang mereka tidak boleh abaikan adalah mereka "mengalami" sendiri berbagai bentuk pengalaman terkait dengan Ida Ratu Gede Mas Mecaling. 
Emik merupakan pandangan sisi masyarakat itu sendiri, tentu saja yang berpandangan positif. Masyarakat Bali melihat bahwa keberadaan Ida Ratu Gede Mas MacalingDalem Nusa Penida ini terkait dengan ilmu kawisesan sekaligus sebagai Bhatara yang utama di dalam Pura Penataran Ped di Nusa Penida. Masyarakat Bali senantiasa memberikan lebel magis dan mistis sambil menyatakan bahwa Ida Ratu Gede Mas Macaling Dalem Nusa Penida merupakan penguasa alam niskala.

Wacana Ida Ratu Gede Mas MacalingDalem Nusa Penida dalam dunia babad merupakan sebuah hal yang paling populer setelah tradisi lisan tersebut. Hal ini karena dunia babad lebih tertulis dan meskipun di pandang sebagai sebuah cacatan yang nilai historisnya tidak seratus persen benar, namun tingkat keyakinan masyarakat terhadap babad sangat tinggi. Untuk kisah cerita Ida Ratu Gede Mas Macaling Dalem Nusa Penida dalam versi babad berasal dari babad Nusa Penida yang disalin oleh Jero Mangku Made Buda (2007) yang bersumber pada Prasasti Babad Nusa Penida, Pidarta Dukuh Jumpungan, kandaning Palua Renggan dan Panugrahan Ratu Macaling.

Mitos di Bali hidup karena tutur yang diberikan oleh para tetua di Bali kepada anak cucu mereka. Tutur dalam hal ini adalah sebuah ajaran, baik berupa cerita, ilmu kawisesan ataupun hal-hal yang terkait langsung dengan sisi batiniah manusia itu sendiri. Mitos Ida Ratu Gede Mas Macaling Dalem Nusa Penida memiliki tutur yang memberikan informasi mengenai ketajaman batin, kekuatan supranatural dan kesaktian yang diluar batas logika manusia biasa. Tutur dalam hal ini memberikan penjelasan mengenai hal tertentu, dan hal tertentu yang dimaksudkan adalah mengenai sisi gaib dan magis dari kisah mitos Ida Ratu Gede Mas Macaling Dalem Nusa Penida.

\section{Fungsi Wacana Ida Ratu Gede Mas \\ Mecaling Dalem Nusa}

Wacana Ida Ratu Gede Mas Mecaling Dalem Nusa dapat dikatakan wacana yang memiliki fungsi beragam yang di dasarkan atas kandungan nilai di dalamnya. Fungsi tersebut tentunya di dasarkan pula atas resepsi 
masyarakat Bali terhadap wacana tersebut sebagai sebuah mitos, legenda bahkan sejarah yang diresepsi sebagai kenyataan yang benarbenar terjadi di masa lampau. Adapun fungsi tersebut adalah menguatkan relasi wacana Ida Ratu Gede Mas Macaling Dalem Nusa terhadap kepercayaan yang gaib dalam kehidupan masyarakat Bali. Hal tersebut disebabkan oleh beberapa faktor, antara lain agama Hindu faktor kuat relasi wacana Ida Ratu Gede Mas Macaling Dalem Nusa terhadap kepercayaan yang gaib, adanya kepercayaan animisme dan dinamisme, dan adanya paradigma sekala dan niskala.

Wacana Ida Ratu Gede Mas Macaling Dalem Nusa Penida Memperkuat Tradisi Perdukunan. Sebab dalam wacana mitologinya, Ida Ratu Gede Mas Macaling Dalem Nusa Penida diyakini oleh paranormal atau dukun di Bali sebagai dewanya atau penguasa ilmu mistisme dan penguasa dunia perdukunan.

Wacana Ida Ratu Gede Mas Macaling Dalem Nusa Penida sebagai penguatan subversif ajaran kawisesan di Bali. Wacana Ida Ratu Gede Mas Macaling Dalem Nusa Penida banyak memberikan ajaran-ajaran kawisesan yang masih dilaksanakan dan berkembang di masyarakat Bali. adapun kawisesan yang dimaksud, ialah kawisesanRudra Murtidan Kanda Sanga. Wacana Ida Ratu Gede Mas Macaling Dalem Nusa Penida penguat kebudayaan lokal Bali. Kebudayaan lokal Bali yang dimaksud adalah tentang adanya Barong Landung sebagai refleksi seni unsur kebudayaan, lontar Dukuh Jumpungan sebagai pengetahuan magis dari unsurBudaya Sastra, dan palinggih Panyawangan Ratu Gede Macaling sebagai sistem religiunsur kebudayaan.

Wacana Ida Ratu Gede Mas Macaling Dalem Nusa Penida sebagai "Kontrol Sosial". Wacana Ida Ratu Gede Mas Mecaling dalam lingkungan sosial masyarakat Bali, nampaknya bukan saja memiliki nilai dan fungsi yang berhubungan dengan hal-hal yang gaib. Tetapi, wacana tersebut hadir sebagai sebuah cara leluhur Bali dalam memaksa berlakunya normanorma sosial, serta sebagai alat pengendali sosial (as a mean of applying social pressure and excerciicing social control). Tawur kaenem penghadiran kekuatan Ida Ratu Gede Mas Macaling Dalem Nusa Penida sebagai penyomya. 
Wacana ini dapat menggerakan masyarakat seluruh desa adat di Bali untuk melaksanakan tradisi ngelawang, yakni Ida Sesuhunan diarak dan diberikan persembahan pada masing-masing batas desa dan perempatan. Selain itu, memasang daun pandan berduri sebagai benteng dan perlindungan, didasarkan pada wacana dari Ida Ratu Gede Mas Macaling Dalem Nusa Penida yang menyatakan bahwa seorang penduduk desa bisa selamat karena dia bersembunyi di semaksemak daun pandan berduri.

Ngelawang penghadiran kekuatan Ida Ratu Gede Mas Macaling Dalem Nusa Penida sebagai kontrol budaya. Prosesi ngelawang adalah bagian dari sebuah ritual yang tentu saja menunjukan bahwa korelasi antara budaya ngelawang itu ada karena wacana ancangan (pengikut) dari Ida Ratu Gede Mas Macaling Dalem Nusa Penida berkunjung ke Bali. Nangluk Mrana sebagai kontrol keyakinan religius. Wacana Ida Ratu Gede Mas Macaling Dalem Nusa Penida memberikan banyak produk budaya semakin berkembang dan didasari atas keyakinan yang kuat.

\section{Makna Wacana Ida Ratu Gede Mas}

\section{Mecaling Dalem Nusa}

Makna dalam wacana mitos Ida Ratu Gede Mas Macaling Dalem Nusa Penida Klungkung bagi lingkungan sosial masyarakat Hindu di Bali, di antara ialah ajaran kelepasan mengarah pada sebuah disiplin ilmu rohani yang mencari tujuan agar menyatu dengan Tuhan Yang Mahaesa. Dalam hal ini, ada perbedaan antara paham ketuhanan pribadi (personal god) dengan Tuhan yang tidak memiliki atribut atau tidak memiliki bentuk dan warna (impersonal god). Wacana magi mitos Ida Ratu Gede Mas Macaling Dalem Nusa Penida, secara langsung memberikan kontribusi besar bagi peletakan dasar konsep kelepasan rohani ini secara psikologis bagi masyarakat Hindu di Bali.

Ajaran penyatuan dalam wacana magi mitos Ida Ratu Gede Mas Macaling Dalem Nusa Penida ini merupakan sebuah ajaran agama Hindu yang memandang bahwa manusia dapat bersatu dengan Tuhannya. Mitos Ida Ratu Gede Mas Macaling Dalem Nusa Penida, merangkum ajaran penyatuan dari dua konsep Tuhan yang berbeda ini. wacana magi 
dari mitos Ida Ratu Gede Mas Macaling Dalem Nusa Penida memberikan porsi yang sama baik pada dvaitavedanta dan advaitavedanta.

Ajaran pangiwa dan panengen bukan diartikan sebagai sebuah ajaran buruk dan ajaran baik. Paradigma yang berkembang di masyarakat Hindu di Bali, ketika ada orang yang berbicara masalah pangiwa, maka langsung bernada buruk. Sedangkan ketika berbicara panengen akan berada dalam sisi kebaikan. Pangiwa dan panengen di sini bukan mengkotakkan antara baik dan buruk. Melainkan memberikan pengertian akan sebuah keseimbangan. Sosok Ida Ratu Gede Mas Macaling Dalem Nusa Penida memang diyakini oleh masyarakat Hindu di Bali sebagai penguasa dari pangiwa dan panengen sekaligus. Anuegrah dari Bhatara Rudra kepada I Gede Macaling menjadikan I Gede Macaling mendapatkan berkah kekuatan yang disebut dengan Panca Taksu.Wacana magis mitos hidup Ida Ratu Gede Mas Macaling Dalem Nusa Penida memberikan makna ajaran kematian sebagai sebuah penyucian. Kematian dalam beberapa pandangan memang merupakan hal yang menakutkan, mengerikan dan masuk dalam tataran sangat sulit dan tabu untuk dibicarakan. Akan berbeda dengan kematian dalam mitos hidup Ida Ratu Gede Mas Macaling Dalem NusaPenida.

\section{DAFTAR PUSTAKA}

Atmaja, Jiwa. 2008. Leak dalam Foklore Bali. Denpasar: CV Bali Media Ahikarsa.

Avalon, Arthur. 2013. Tantra the Sakti Power. USA. New York University Press.

Dibyasuharda.1990. Dimensi Metafisik Dalam Simbol Ontologi Mengenai Akar Simbol. Yogyakarta: UGM Yogyakarta.

Endraswara, Suwardi.2010. Metedologi

Penelitian Sastra. Yogyakarta: Pustaka Pelajar.

Ghazali, Muchtar Muhamad.2011. Antropologi Agama Upaya Memahami Keragaman Kepercayaan, keyakinan dan Agama. Bandung: ALFABETA.

Kiven, Lydya. 2016. Menelusuri Figur Bertopi Dalam Relief Candi Zaman Majapahit. Jakarta: Kepustakaan Populer Gramedia. 
Koentjaraningrat.1987. Sejarah Antropologi

I. Jakarta:Anggota IKAPI.

Saputra, Kanduk.2008. Mitos Ida Ratu Gede Mecaling (dalam Majalah Taksu.2008.Edisi ke 233). Denpasar: TaksuBali.

Sobur, Adi.2009. Teori Semiotika Sastra, Teori dan Aplikasinya. Yogyakarta: LKIS.

Subagia, I Made.2016. Ritual Tantrik Ngereh Dalam Budaya Bali. Denpasar: Pustaka Manik Geni. 
Sukayasa I Wayan.2007. Teori Rasa Memahami Taksu, Ekspresi dan Metodenya. Denpasar: Program Magister Ilmu Agama dan Kebudayaan UNHI.

Wiarawan, Komang Indra. 2017. Bunga Rampai Pemikiran Jero Mangku Wayan Candra Upacara Yadnya Mepandes dan Mitologi Ida Ratu Gede Mas Mecaling. Denpasar: Gases Bali Vissual.

Zoetmulder. PJ.1983. Kalangwan Satsra Jawa Kuno Selayang Pandang. Jakarta: Djambatan. 